\title{
Impact of chemical pre-treatments on the acrylamide formation and sensorial quality of potato crisps
}

\author{
Frédéric Mestdagh ${ }^{\mathrm{a}, \mathrm{b}}$, Tineke De Wilde ${ }^{\mathrm{a}}$, Karel Delporte ${ }^{\mathrm{a}}$, \\ Carlos Van Peteghem ${ }^{\mathrm{b}}$, Bruno De Meulenaer ${ }^{\mathrm{a}, *}$ \\ a Department of Food Safety and Food Quality, Faculty of Bioscience Engineering, Ghent University, Coupure Links 653, B-9000 Ghent, Belgium \\ ${ }^{\mathrm{b}}$ Department of Bioanalysis, Faculty of Pharmaceutical Sciences, Ghent University, Harelbekestraat 72, B-9000 Ghent, Belgium
}

Received 19 May 2007; received in revised form 27 June 2007; accepted 2 July 2007

\begin{abstract}
Several components were added to the blanching water of potato crisps. Calcium ions, sodium acid pyrophosphate, citric, acetic and L-lactic acid significantly reduced the final acrylamide content, as well as free glycine and L-lysine. The acids, $\mathrm{NaCl}$ and calcium-containing additives also lowered the oil absorption, which may have led to a reduced heat transfer and acrylamide contamination in the final product. Textural and compositional product changes may thus also influence acrylamide formation. By means of sensory analyses of these crisps, a successful combination was demonstrated between acrylamide mitigating treatments and crisps of acceptable or even superior product quality, compared to control crisps blanched in water. However, the applied components and concentration levels should be well chosen in order not to generate product-foreign flavours or undesired product colour.
\end{abstract}

(c) 2007 Elsevier Ltd. All rights reserved.

Keywords: Acrylamide; pH; Pre-treatments; Sensory analysis; Potato crisps

\section{Introduction}

Acrylamide is a suspected human carcinogen, formed in fried and baked carbohydrate-rich foodstuffs such as potatoes. Its formation pathway is linked with the Maillard reaction. The free amino acid asparagine and reducing sugars are considered as the main precursors (Stadler et al., 2004). A number of raw material pre-treatments were investigated which could mitigate acrylamide formation. These techniques include the extraction of acrylamide precursors by soaking or blanching in water or in acidic solutions (Kita, Bråthen, Knutsen, \& Wicklund, 2004; Pedreschi, Kaack, \& Granby, 2004; Pedreschi, Kaack, Granby, \& Troncoso, 2007).

In a previous study (Mestdagh et al., 2007), the impact of several additives on the formation of acrylamide in a

\footnotetext{
* Corresponding author. Tel.: +32926461 66; fax: +3292646215.

E-mail address: Bruno.DeMeulenaer@UGent.be (B.D. Meulenaer).
}

potato model system was investigated. The addition of the free amino acids glycine and L-lysine to the potato powder model system lowered the final acrylamide content, while keeping the $\mathrm{pH}$ at its original level. It was suggested that these components would reduce acrylamide formation by promoting competitive reactions and/or by covalently binding the formed acrylamide through Michael type addition reactions (Claeys, De Vleeschouwer, \& Hendrickx, 2005; Kim, Hwang, \& Lee, 2005; Low et al., 2006).

Furthermore, organic acids, such as citric, acetic and Llactic acid reduced the final acrylamide content, but merely due to a reduced $\mathrm{pH}$ (Mestdagh et al., 2007). Calcium ions induced a supplementary acrylamide reduction, not attributed to a lower $\mathrm{pH}$. Previously, the mitigating effect at low $\mathrm{pH}$ was attributed to protonation of asparagine amino groups. This would block the nucleophilic addition of asparagine with a carbonyl compound, preventing the formation of the corresponding Schiff base, a key intermediate in the Maillard reaction and in the formation of acrylamide (Kita et al., 2004; Pedreschi et al., 2004; Pedreschi et al., 
2007). Also $\mathrm{Na}^{+}$or $\mathrm{Ca}^{2+}$ were indicated to interact with asparagine to prevent the formation of acrylamide (Park et al., 2005; Lindsay \& Jang, 2005; Gökmen \& Senyuva, 2007). Yet, in the previous study, $\mathrm{NaCl}$ did not lower the final acrylamide content in the potato model system (Mestdagh et al., 2007). On the other hand, the addition of $\mathrm{NaCl}$, $\mathrm{CaCl}_{2}$ or citric acid might also change the oil uptake (Bunger, Moyano, \& Rioseco, 2003; Rimac-Brncic, Lelas, Rade, \& Simundic, 2004; Pedreschi, Moyano, Santis, \& Pedreschi, 2007). This could therefore be an additional factor, possibly influencing the formation of acrylamide in fried foodstuffs.

Unfortunately above-mentioned treatments may also have an impact on the sensorial product quality, since low $\mathrm{pH}$ also suppresses the Maillard reaction, responsible for the generation of desirable flavours and colours. Acidification may moreover result in a sour product taste (Kita et al., 2004; Franke, Sell, \& Reimerdes, 2005). This effect however depends upon the applied soaking or blanching treatment and the type and concentration of the acid used. It was suggested that acetic acid would be a better acidulant for the pre-treatment of potato crisps compared to citric acid, due to the less appearing sourness (Kita et al., 2004). Addition of (sulphur containing) amino acids may also generate unpleasant off-flavours upon heating, which should be taken into account as well (Claeys et al., 2005). Calcium chloride might improve product texture, but on the other hand can cause a bitter aftertaste (Varela, Salvador, \& Fiszman, 2007). Consequently, these pre-treatments may also cause unwanted sensorial defects. To date few investigations have however been published specifically concerning the effect on the integral sensorial properties of the final product, when mitigating acrylamide formation. To our knowledge, studies performing profound sensorial testing using taste panels have even not been reported yet in this context.

Therefore, the main purpose of this investigation was to confirm the acrylamide-lowering impact of several additives, already commonly used in the food industry. These components were dissolved in the blanching water of potato crisps. In addition, the impact on the sensorial quality of the most efficient treatments was evaluated on potato crisps by means of a surface colour measurement and a sensory panel. The challenge of this study was thus to find strategies to minimize acrylamide formation while maintaining the expected product quality for the consumer.

\section{Materials and methods}

\subsection{Reagents and chemicals}

$\mathrm{HCl}(25 \% \mathrm{w} / \mathrm{w})$ and petroleum ether (bp $40-60{ }^{\circ} \mathrm{C}$, Chem-Lab, Belgium) were used for the determination of the oil content. $\mathrm{K}_{2} \mathrm{CrO}_{4}$ and $\mathrm{AgNO}_{3}$ were (Merck, Darmstadt, Germany) were applied for the salt content determination. $\mathrm{CaCl}_{2}(36 \% \mathrm{w} / \mathrm{v})$ and citric acid $(>99.8 \% \mathrm{w} / \mathrm{w})$ were supplied by Brenntag (Belgium), while L-lactic acid
$(50 \% \mathrm{w} / \mathrm{v})$ was provided by Purac Biochem (The Netherlands). In addition, two products containing calcium-L-lactate and calcium chloride were provided by Purac Biochem. The first one, named Ca100, contained $24.5 \%$ calcium (w/ $\mathrm{w}$ ), while the second, named Ca200, contained 20.8\% calcium (w/w). $\mathrm{NaCl}(>99 \% \mathrm{w} / \mathrm{w})$ and acetic acid were bought in retail, the latter as vinegar $(7 \% \mathrm{v} / \mathrm{v})$. Glycine, L-glutamine and L-lysine $(>99.8 \% \mathrm{w} / \mathrm{w})$ were supplied by Sigma Aldrich (Belgium). Sodium acid pyrophosphate $\left(\mathrm{Na}_{2} \mathrm{H}_{2} \mathrm{P}_{2} \mathrm{O}_{7}>95 \%\right.$ w/w) was delivered by Sibeco (Belgium). All products used during sensory analysis were of food grade quality. All reagents and chemicals used for the acrylamide analysis were described in Mestdagh et al. (2005).

\subsection{Preparation of potato crisps}

Potatoes (Solanum tuberosum L.), variety Bintje, were cut in slices of $1.5 \mathrm{~mm}$ thickness and washed five times under distilled water. In order to perform each frying experiment in a repeatable manner, a large homogeneous batch of raw potato slices with similar size was prepared at the beginning of each series of experiments. The slices were subsequently blanched in distilled water or in solutions containing different compounds in various concentrations for exactly $5 \mathrm{~min}$ at $65^{\circ} \mathrm{C}$. The potato/solution ratio was $0.1(\mathrm{w} / \mathrm{w})$ and was deliberately kept constant. After superficially drying on a paper towel, the $\mathrm{pH}$ was determined on a part of the blanched slices, adding $90 \mathrm{~mL}$ of distilled carbon dioxide free water to $10 \mathrm{~g}$ of homogenized potato. After $10 \mathrm{~min}$ incubation, the $\mathrm{pH}$ of the slurry was measured (Schott, Germany). About $50 \mathrm{~g}$ of the remaining slices were fried for $3 \mathrm{~min}$ at $170{ }^{\circ} \mathrm{C}$ in a deep-fryer (Fritel 2505, Belgium). Directly after frying, the crisps were cooled on an absorbing paper and the surface colour was measured. A part of the batch was thoroughly homogenized for acrylamide analysis, while another part was used for sensory analysis.

\subsection{Determination of oil content}

About $10 \mathrm{~g}$ of homogenized potato crisps was boiled for $15 \mathrm{~min}$ in a beaker containing $50 \mathrm{~mL} \mathrm{HCl}(25 \%)$ and covered with a watch glass. The solution was filtered over a wet filter paper. The filter was rinsed with hot water until the filtrate reached a neutral $\mathrm{pH}$ and dried. The oil was Soxhlet extracted with $150-200 \mathrm{~mL}$ petroleumether during $4 \mathrm{~h}$. After solvent evaporation, the oil residue was dried until constant weight at $105^{\circ} \mathrm{C}$ (Egan, Kirk, \& Sawyer, 1981).

\subsection{Determination of salt content}

The salt content was measured by means of a precipitation titration with silver nitrate. Accordingly, the amount of chlorides was determined in an aqueous extract, which is correlated with the amount of sodium present (Paul \& Southgate, 1978). 


\subsection{Acrylamide analysis}

Acrylamide was determined by LC-MS/MS as described earlier (Mestdagh et al., 2005). After aqueous extraction, using $\left[2,3,3-\mathrm{D}_{3}\right]$ acrylamide as internal standard, the acrylamide extract was further cleaned-up by solid phase extraction. The extract was analyzed using LC-MS/MS with positive electrospray ionization.

\subsection{Sensory analysis}

The potato crisps were subjected to a quantitative descriptive analysis (QDA), performed according to ISO 6658 (2005). Although most of the assessors were already acquainted with similar sensory analyses and were trained and selected in previous studies, a preliminary set of training sessions was carried out. Accordingly, 21 assessors were familiarized with the scoring system, the foodstuff to be evaluated and the sensory vocabulary. By means of potato crisps, blanched in solutions containing several amounts of acids, amino acids or salts, the relevance of each descriptor was discussed and the most important descriptive terms were retained. The degree of sourness was trained using crisps blanched in citric and acetic acid solutions. For the saltiness and bitterness, crisps blanched in respectively $\mathrm{NaCl}$ and $\mathrm{CaCl}_{2}$ solutions were used, while for the popcorn-like taste, L-lysine was applied at several concentrations. Water-blanched crisps were used as the reference potato crisp. During each session, with about 18 assessors, this reference product was openly included as a sort of calibration standard for the assessors and as a remainder of the meaning of the previously agreed scores for each descriptor (Carpenter, Lyon, \& Hasdell, 2000). Therefore, these scores were also indicated on the rating scales. However, to check the assessor's performance, this reference product was also included as a blind control during each session (Carpenter et al., 2000).

Product texture and taste were evaluated under IR-light in a special room with individual booths. Snap was defined as the textural perception at the first bite, while crispness was perceived upon subsequent chewing. Concerning the taste, the product sourness, saltiness and bitterness was evaluated, besides popcorn-like flavour and taste of fried potato. Each of these descriptors was evaluated using a continuous line scale with five anchor points, being 0 (absent), 2.5 (slightly present), 5 (moderately present), 7.5 (strongly present) and 10 (very strongly present). The distance between the origin and the point, indicated by the panellist was measured and standardized to scores between 0 and 10 . The product acceptability was also evaluated under IR light, based on the taste only ("taste appraisal") and based on both product texture and taste ("overall appraisal"). For this hedonic evaluation, a similar five anchor line scale was used, ranging from zero (dislike very much), over 5 (neither like nor dislike) to 10 (like very much). Consequently, a product with a score above 5 could be considered as acceptable. Water was provided to cleanse the palate in between two tests.

\subsection{Colour evaluation}

Crisp surface colour was measured using a Konica Minolta spectrophotometer CM-2500d (Konica Minolta, Japan), operating in the CIE $L^{*} a^{*} b^{*}$ colour space. The colour is defined by three orthogonal co-ordinates. $L^{*}$ is the lightness component. Parameters $a^{*}$ (from green to red) and $b^{*}$ (from blue to yellow) are the two chromatic components. Immediately after cooling down, several potato crisps were placed on a white paper. The readings were carried out in fifteen fold placing the instrument measuring port ( $8 \mathrm{~mm}$ aperture) at both sides of the crisps. In such a way, the reflectance of a representative part of the surface was measured. Specular reflectance was included in the colour measurement. Following measurement conditions were applied: UV $100 \%$; standard illuminant D65 and observer angle $10^{\circ}$. The instrument was calibrated with a white calibration tile and black calibration box. Data acquisition was performed using the Spectramagic NX colour data software, version 1.52 (Japan). Crisp colour was expressed as the change in surface colour $(\Delta E)$ compared to the raw potato. $\Delta E$ was calculated by following formula $\Delta E=\left[\left(L_{0}^{*}-L^{*}\right)^{2}+\left(a_{0}^{*}-a^{*}\right)^{2}+\left(b_{0}^{*}-b^{*}\right)^{2}\right]^{1 / 2}$. The $L_{0}^{*} a_{0}^{*} b_{0}^{*}$ values correspond to the raw potato slices while the $L^{*} a^{*} b^{*}$ values correspond to the measurements of the different fried products.

\subsection{Statistical analysis}

The repeatability of the deep-frying procedure was previously evaluated, yielding a variation coefficient of $15 \%$, which was used to calculate the $95 \%$ confidence intervals for the acrylamide contents in the crisps. The sensory analyses were statistically evaluated using analysis of variance (One-way ANOVA) using SPSS 12.0 (SPSS Inc., Chicago, IL, USA). Significant differences among means of treatments were evaluated by the post hoc multiple comparison Tukey test with statistical significance established at $P \leqslant 0.05$ (O'Mahony, 1986). Pearson correlation analysis was also performed to determine linear relationships between sensory attributes.

\section{Results and discussion}

\subsection{Influence of additives in blanching water on acrylamide formation in potato crisps}

The most effective acrylamide-lowering agents, investigated in previous study (Mestdagh et al., 2007), were evaluated on potato crisps. Prior to frying, different components were diffused into the potato slices by means of a blanching step at $65^{\circ} \mathrm{C}$ for $5 \mathrm{~min}$. These conditions were applied since they resemble an industrial blanching process of potato crisps. In addition, this blanching treat- 
ment led to the preparation of potato crisps with an acceptable sensory quality, such as crispiness, taste and colour. From literature, it appeared that the large product surface and the applied blanching temperatures caused a more efficient acrylamide reduction compared to soaking treatments performed at lower temperatures, due to a higher diffusion of acrylamide precursors from the potato tissue and due to a more efficient diffusion of additives into the slices (Kita et al., 2004; Pedreschi et al., 2004; Pedreschi et al., 2007). For each treatment, the acrylamide-lowering effect was determined, comparing the acrylamide content with the content in potato crisps, blanched in distilled water prior to frying (Table 1). The measured $\mathrm{pH}$ of these crisps, blanched in distilled water, was 6.7.

Table 1 shows the acrylamide-lowering effect of the blanching treatments, as well as the final oil content, the $\mathrm{pH}$ of the blanching solutions and of the blanched potato slices. Components were added to the blanching solutions in concentrations of $0.025,0.05$ or $0.1 \mathrm{M}$. Similar to previous study (Mestdagh et al., 2007), three organic acids were evaluated, being citric, acetic and L-lactic acid. At a concentration of $0.1 \mathrm{M}$, all three acids completely eliminated the formation of acrylamide. At $0.05 \mathrm{M}$, only acetic acid did not totally reduce acrylamide, due to the less pronounced $\mathrm{pH}$ lowering capacity of this organic acid, as compared to the other two. In addition, acetic acid is more volatile compared to the other organic acids investigated, leading to a more pronounced evaporation upon frying. The different $\mathrm{pH}$ of the potato slices also determined the acrylamide mitigating capacity at the lowest concentration level investigated in the blanching water, being $0.025 \mathrm{M}$. Moreover, the final oil content decreased to about 25$29 \%$ in comparison with the control, blanched in water.

Furthermore, the acrylamide-lowering effect was investigated in potato crisps upon addition of free glycine and L-lysine to the blanching water, at different concentration levels (Table 1). It was shown in a previous study that addition of these components did not markedly change the $\mathrm{pH}$ of the potato (Mestdagh et al., 2007), which was also observed in the current experiments at the $0.05 \mathrm{M}$ level (Table 1). At this concentration level, these additives did not show to markedly influence the final oil content of the crisps, compared to the control. L-lysine appeared to reduce more efficiently the formation of acrylamide, although the differences were less pronounced at the 0.05 and $0.025 \mathrm{M}$ concentration levels, as was observed in the model system (Mestdagh et al., 2007).

Similar to the experiments performed in the potato model (Mestdagh et al., 2007), several combinations of amino acids with organic acids were evaluated (Table 1). Since a total acrylamide reduction could already be obtained using only citric acid, the effect of additional amino acids was not noted. Again, the mitigation appeared to be higher in the crisps treated with acid and L-lysine, compared to the crisps blanched in acid-glycine solutions. Although the acrylamide reductions were not always more pronounced for the combined treatments of acids and amino acids, these combinatory treatments could improve product appearance, by promoting Maillard browning (Low et al., 2006), as evaluated further on.

In contrast to the experiments with the potato model system (Mestdagh et al., 2007) and in accordance with previous reports (Franke et al., 2005; Pedreschi et al., 2007), $\mathrm{NaCl}$ significantly decreased the acrylamide content (Table 1). Moreover, at the highest concentration level, applied in the blanching water $(0.1 \mathrm{M})$, the final salt content in the crisps $\left(3.5 \mathrm{~g} \mathrm{~kg}^{-1}\right.$ crisp) still appeared to be only half of the amount being present in salted crisps, sold in retail. Also the oil content was significantly reduced $(27 \%)$ by $\mathrm{NaCl}$ addition to the blanching water. Furthermore, it was previously demonstrated that acrylamide formation decreased upon lowering the oil content of the potato model system, probably due to a lower heat transfer from the oil to the system (Mestdagh et al., 2005). Therefore, a decreased oil uptake seems a plausible mechanism behind acrylamide reduction in the $\mathrm{NaCl}$ treated crisps. Also $\mathrm{CaCl}_{2}$ mitigated acrylamide formation, although only a marginal decrease was observed at the lowest concentration level $(0.025 \mathrm{M})$. Moreover, a similar decrease in oil content was observed as for the $\mathrm{NaCl}$ treated crisps. Sodium acid pyrophosphate $\left(\mathrm{Na}_{2} \mathrm{H}_{2} \mathrm{P}_{2} \mathrm{O}_{7}\right)$ appeared to be effective as well in reducing acrylamide, due to a mild reduction in $\mathrm{pH}$ of the raw potato slices. Also a lower oil content was observed compared to the control, blanched in water. The currently applied concentration of sodium acid pyrophosphate in industry is however only about $2.5 \mathrm{mM}$, probably leading to less pronounced reductions of the $\mathrm{pH}$ and acrylamide content.

Furthermore, two commercially available combinations of $\mathrm{CaCl}_{2}$ and calcium-L-lactate were investigated, named Ca100 and Ca200. As shown in Table 1, the applied molar concentrations, calculated for the calcium ions, were different compared to $\mathrm{CaCl}_{2}$ since the exact composition was not known at the time of research. Ca100 however appeared to contain $24.5 \%$ calcium $(\mathrm{w} / \mathrm{w})$, while the second one only contained $20.8 \%$ calcium $(\mathrm{w} / \mathrm{w})$. This difference in calcium dosage was also visible in the acrylamide-lowering effect. A linear correlation was even observed $\left(R^{2}=0.86\right)$ between the percentage acrylamide reduction and the molar concentration of calcium ions, applied in the blanching solutions. The oil contents were however similar between the different calcium treatments. Since there was less calcium present in the Ca200 product, acrylamide was less efficiently reduced compared to the Ca100 product, although the differences were not significant (Table 1).

A reduced oil absorption was thus assessed for the crisps treated with acids, $\mathrm{NaCl}$ or calcium-containing components, as was reported previously (Khalil, 1999; Bunger et al., 2003; Rimac-Brncic et al., 2004). From earlier studies (Aguilar, AnzalduaMorales, Talamas, \& Gastelum, 1997), low-temperature blanching also appeared to lower the final oil content of deep-fried products. These processes or additives may change important textural characteristics such as the product surface roughness and crust porosity, leading 
Table 1

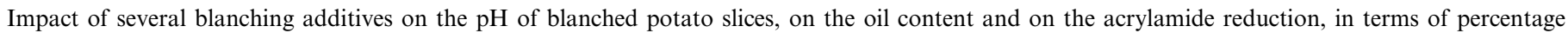
compared to water-blanched crisps

\begin{tabular}{|c|c|c|c|c|c|}
\hline Components added to blanching water & Concentration $\left(\mathrm{mol} \mathrm{L}^{-1}\right)$ & $\mathrm{pH}$ blanching water & $\begin{array}{l}\mathrm{pH} \text { blanched } \\
\text { potato slices }\end{array}$ & $\begin{array}{l}\text { Oil content } \\
(\%)\end{array}$ & $\begin{array}{l}\text { Acrylamide } \\
\text { reduction }(\%)^{\mathrm{a}}\end{array}$ \\
\hline Water (control) & & 7.1 & 6.7 & 40 & 0 \\
\hline \multirow[t]{3}{*}{ Citric acid } & 0.1 & - & - & - & $100( \pm 16)$ \\
\hline & 0.05 & 2.3 & 3.4 & - & $100( \pm 16)$ \\
\hline & 0.025 & 2.5 & 4.1 & 25 & $98( \pm 15)$ \\
\hline \multirow[t]{3}{*}{ Acetic acid } & 0.1 & - & - & - & $100( \pm 16)$ \\
\hline & 0.05 & 3.7 & 4.6 & - & $79( \pm 13)$ \\
\hline & 0.025 & 3.8 & 4.8 & 29 & $80( \pm 13)$ \\
\hline \multirow[t]{3}{*}{ L-lactic acid } & 0.1 & - & - & - & $100( \pm 16)$ \\
\hline & 0.05 & 2.9 & 3.9 & - & $100( \pm 16)$ \\
\hline & 0.025 & 3.2 & 4.8 & 29 & $89( \pm 14)$ \\
\hline \multirow[t]{3}{*}{ Glycine } & 0.1 & - & - & - & $68( \pm 11)$ \\
\hline & 0.05 & 7.5 & 6.6 & 35 & $63( \pm 10)$ \\
\hline & 0.025 & - & - & - & $58( \pm 9)$ \\
\hline \multirow[t]{3}{*}{ L-lysine } & 0.1 & - & - & - & $85( \pm 13)$ \\
\hline & 0.05 & 7.1 & 6.6 & 38 & $63( \pm 10)$ \\
\hline & 0.025 & - & - & - & $73( \pm 12)$ \\
\hline Citric acid + glycine & $0.05+0.05$ & - & - & - & $97( \pm 15)$ \\
\hline Citric acid + L-lysine & $0.05+0.05$ & - & - & - & $99( \pm 16)$ \\
\hline \multirow[t]{2}{*}{ Acetic acid + glycine } & $0.05+0.05$ & - & - & - & $81( \pm 13)$ \\
\hline & $0.025+0.05$ & - & - & - & $71( \pm 11)$ \\
\hline \multirow[t]{2}{*}{ Acetic acid + L-lysine } & $0.05+0.05$ & - & - & - & $89( \pm 14)$ \\
\hline & $0.025+0.05$ & - & - & - & $75( \pm 12)$ \\
\hline \multirow[t]{2}{*}{$\mathrm{NaCl}$} & 0.1 & 7.8 & 6.7 & 27 & $43( \pm 7)$ \\
\hline & 0.05 & - & - & - & $28( \pm 4)$ \\
\hline \multirow[t]{2}{*}{$\mathrm{Na}_{2} \mathrm{H}_{2} \mathrm{P}_{2} \mathrm{O}_{7}$} & 0.1 & - & - & - & $90( \pm 14)$ \\
\hline & 0.05 & 4.7 & 6.0 & 29 & $83( \pm 13)$ \\
\hline \multirow[t]{3}{*}{$\mathrm{CaCl}_{2}$} & 0.1 & 7.2 & 6.5 & - & $93( \pm 15)$ \\
\hline & 0.05 & 7.5 & 6.1 & 24 & $64( \pm 10)$ \\
\hline & 0.025 & - & - & - & $17( \pm 3)$ \\
\hline \multirow[t]{2}{*}{ Ca100 } & $0.07^{\mathrm{b}}$ & 7.7 & 6.5 & - & $82( \pm 13)$ \\
\hline & $0.04^{\mathrm{b}}$ & 7.6 & 6.3 & 23 & $50( \pm 8)$ \\
\hline \multirow[t]{2}{*}{$\mathrm{Ca} 200$} & $0.06^{\mathrm{b}}$ & 7.7 & 6.7 & - & $72( \pm 11)$ \\
\hline & $0.03^{\mathrm{b}}$ & 7.6 & 6.3 & 23 & $45( \pm 7)$ \\
\hline
\end{tabular}

-: Measurements not performed.

${ }^{a}$ Compared to potato crisps, blanched in water (control). 95\% Confidence intervals are mentioned between brackets.

b Molar concentration, calculated for the calcium ion.

to a different oil uptake (Aguilar et al., 1997; Khalil, 1999) and eventually also to different acrylamide contents, as clearly shown for $\mathrm{NaCl}$. Furthermore, it is known that the oil is mostly absorbed at the end of the frying process (Miranda \& Aguilera, 2006). Interestingly, this is also the stage during which significant acrylamide formation takes place, as the surface is drier, which moreover allows the temperature to rise far above $100{ }^{\circ} \mathrm{C}$ (Grob et al., 2003; Jackson \& Al-Taher, 2005). Consequently, besides chemical interactions with the acrylamide formation mechanisms, some additives may also change structural properties of the potato tissue, which may lead to a different oil uptake and concomitantly altered heat transfer and acrylamide formation in the foodstuff.

\subsection{Preliminary sensorial appraisal of potato crisps}

In order to evaluate the sensorial acceptability of the potato crisps and before serving these snacks to a sensory panel, the authors tasted the crisps mentioned in Table 1.
Sodium acid pyrophosphate was not of food grade quality and consequently not evaluated. This brief appraisal learned that the crisps, blanched in water were quite tasty.

The organic acids and especially citric acid rendered the product quite sour at the highest concentrations applied. Since acrylamide was also very efficiently reduced at the lowest concentrations $(0.025 \mathrm{M})$, this concentration level was selected for a more extensive evaluation by the sensory panel. This concentration level was also chosen for a combined treatment of acetic acid with the amino acids glycine and L-lysine.

Potato crisps with added glycine and L-lysine were of acceptable quality. However, at concentration levels of $0.1 \mathrm{M}$, an unusual popcorn-like taste was perceived for the L-lysine-treated crisps. Since this taste is not associated with potato crisps by the consumer, the crisps at a lower concentration level of $0.05 \mathrm{M}$ glycine and L-lysine were retained for further sensory evaluation, providing still a significant acrylamide reduction of $63 \%$ compared to the water-blanched control (Table 1). 
For $\mathrm{NaCl}$, the highest concentration level was selected for further analysis, since the salty taste is product-familiar. It moreover led to a significant acrylamide reduction (Table 1). At $0.1 \mathrm{M}$, a bitter aftertaste was however perceived in the $\mathrm{CaCl}_{2}$ treated products, which was much less pronounced at $0.05 \mathrm{M}$. This concentration level was consequently retained for more elaborate sensory analysis, as discussed below. Similarly, Ca100 and Ca200 were also included at a concentration level of 0.04 and $0.03 \mathrm{M}$ calcium.

\subsection{Extensive sensory evaluation of potato crisps by taste panel}

A sensory panel evaluated the selected potato crisps, based on several descriptors linked with product texture and taste (Table 2). Water-blanched crisps were provided and indicated as the reference product. These so-called control crisps were also included as a blind control during each session. The scores attributed by the panellists to this blind control were not significantly different from the previously agreed scores for this product, indicating the consistent use of the rating scales (Carpenter et al., 2000). The overall appraisal of these crisps was 5.5, which is above the limit of acceptability, being 5. However, it has to be mentioned that the sensory quality of these crisps could not directly be compared with commercial crisps, since no flavourings were added to the evaluated products, as is usually done.

Concerning the addition of acids, the sensory panel detected a sour taste only for the crisps, blanched in $0.025 \mathrm{M}$ citric acid (Table 2). Apparently, this sourness also led to a significantly lower perception of the fried potato taste. Consequently these crisps were rejected, as can be observed from the low taste and low general appraisal scores, which were significantly lower compared to the control. Yet, the crisps treated with acetic and lactic acid were not significantly different from the control, as was the case for the crisps blanched in $0.05 \mathrm{M}$ glycine or L-lysine. These products scored even higher on taste and overall appraisal, although not significantly compared to the control. Addition of $\mathrm{NaCl}$ led to a more salty product taste, but this did not change the appraisal scores, compared to the control.

For the potato crisps, blanched in solutions containing both acetic acid and glycine or L-lysine, no sour taste was perceived, similar to crisps blanched in acetic acid only (Table 2). The crisps treated with acetic acid and glycine were not significantly different compared to the control. However, for the crisps blanched in water containing acetic acid and L-lysine, an unpleasant popcorn-like taste was perceived, which is unfamiliar for potato crisps. Moreover, this taste suppressed the fried potato taste. Therefore, this product was clearly rejected by the panellists.

The addition of calcium clearly provoked a more crispy texture, as could be concluded from the significantly higher snap and crispness scores for $\mathrm{CaCl}_{2}, \mathrm{Ca} 100$ and Ca200, compared to the control crisps (Table 2). This was appreciated by the panellists as could be observed from the higher appraisal scores, around 7. The bitter aftertaste, which was perceived by the authors during preliminary sensory evaluation of crisps treated with $0.1 \mathrm{M}$ $\mathrm{CaCl}_{2}$, was not detected by the panellists at the lower molar concentration.

Table 3 shows the correlation between the sensory scores, attributed by the panellists to evaluate the crisps. A significant correlation was found between both textural descriptors, snap and crispness, as well as between the taste and general appraisal. From this table, it can furthermore be concluded that the product crispness, snap and fried potato taste were positively correlated with the taste and overall appraisal. Sourness showed a negative correlation with the product appreciation parameters, as well as with the fried potato taste. The latter was also the case for bitterness and popcorn-like flavours. Apparently, these foreign flavours induced the suppression of the regular taste of fried potatoes, leading to unacceptable final product quality.

Table 2

Mean sensory scores (evaluated by taste panel) and surface colour (evaluated with spectrophotometer) of potato crisps, having experienced blanching treatments in water to which several components were added

\begin{tabular}{|c|c|c|c|c|c|c|c|c|c|c|c|}
\hline \multirow{2}{*}{$\begin{array}{l}\text { Components added to } \\
\text { blanching water }\end{array}$} & \multirow{2}{*}{$\begin{array}{l}\text { Concentration } \\
\left(\mathrm{mol} \mathrm{L}^{-1}\right)\end{array}$} & \multicolumn{2}{|c|}{ Texture } & \multicolumn{5}{|l|}{ Taste } & \multirow{2}{*}{$\begin{array}{l}\text { Taste } \\
\text { appraisal }\end{array}$} & \multirow{2}{*}{$\begin{array}{l}\text { Overall } \\
\text { appraisal }\end{array}$} & \multirow{2}{*}{$\begin{array}{l}\text { Surface } \\
\text { colour }(\Delta E)\end{array}$} \\
\hline & & Snap & Crispness & Potato & Sour & Salt & Bitter & Popcorn & & & \\
\hline Water (control) & & $6.7^{\mathrm{a}}$ & $6.8^{\mathrm{a}}$ & $6.6^{\mathrm{bc}}$ & $0.0^{\mathrm{a}}$ & $0.2^{\mathrm{a}}$ & $0.0^{\mathrm{a}}$ & $0.1^{\mathrm{a}}$ & $5.7^{\mathrm{bc}}$ & $5.5^{\mathrm{bcd}}$ & $7.9^{\mathrm{bc}}$ \\
\hline Citric acid & 0.025 & $7.6^{\mathrm{abc}}$ & $7.5^{\mathrm{abc}}$ & $2.6^{\mathrm{a}}$ & $5.5^{\mathrm{b}}$ & $0.0^{\mathrm{a}}$ & $0.1^{\mathrm{a}}$ & $0.3^{\mathrm{a}}$ & $1.7^{\mathrm{a}}$ & $1.8^{\mathrm{a}}$ & $6.5^{\mathrm{c}}$ \\
\hline Acetic acid & 0.025 & $8.1^{\mathrm{abc}}$ & $8.3^{\mathrm{abc}}$ & $4.6^{\mathrm{ab}}$ & $0.2^{\mathrm{a}}$ & $0.0^{\mathrm{a}}$ & $0.5^{\mathrm{a}}$ & $0.0^{\mathrm{a}}$ & $5.6^{\mathrm{bc}}$ & $5.2^{\mathrm{bc}}$ & $7.4^{\mathrm{c}}$ \\
\hline Lactic acid & 0.025 & $8.3^{\mathrm{abc}}$ & $8.5^{\mathrm{abc}}$ & $6.3^{\mathrm{bc}}$ & $0.3^{\mathrm{a}}$ & $0.0^{\mathrm{a}}$ & $0.1^{\mathrm{a}}$ & $0.0^{\mathrm{a}}$ & $5.3^{\mathrm{bc}}$ & $5.3^{\mathrm{bc}}$ & $11.4^{\mathrm{ab}}$ \\
\hline Glycine & 0.05 & $7.7^{\mathrm{abc}}$ & $7.6^{\mathrm{abc}}$ & $6.3^{\mathrm{bc}}$ & $0.0^{\mathrm{a}}$ & $0.5^{\mathrm{a}}$ & $0.5^{\mathrm{a}}$ & $0.0^{\mathrm{a}}$ & $5.9^{\mathrm{bc}}$ & $6.0^{\text {bcd }}$ & $12.0^{\mathrm{ab}}$ \\
\hline L-lysine & 0.05 & $7.9^{\mathrm{abc}}$ & $8.0^{\mathrm{abc}}$ & $6.7^{\mathrm{bc}}$ & $0.0^{\mathrm{a}}$ & $0.2^{\mathrm{a}}$ & $0.3^{\mathrm{a}}$ & $0.2^{\mathrm{a}}$ & $6.6^{\mathrm{c}}$ & $6.6^{\mathrm{cd}}$ & $14.4^{\mathrm{a}}$ \\
\hline Acetic acid + glycine & $0.025+0.05$ & $7.8^{\mathrm{abc}}$ & $7.9^{\mathrm{abc}}$ & $6.8^{\mathrm{bc}}$ & $0.0^{\mathrm{a}}$ & $0.2^{\mathrm{a}}$ & $0.4^{\mathrm{a}}$ & $0.1^{\mathrm{a}}$ & $6.5^{\mathrm{c}}$ & $6.8^{\mathrm{cd}}$ & $8.3^{\mathrm{bc}}$ \\
\hline Acetic acid + L-lysine & $0.025+0.05$ & $8.3^{\mathrm{abc}}$ & $8.4^{\mathrm{abc}}$ & $3.5^{\mathrm{a}}$ & $0.1^{\mathrm{a}}$ & $0.2^{\mathrm{a}}$ & $0.1^{\mathrm{a}}$ & $6.1^{\mathrm{b}}$ & $4.2^{\mathrm{b}}$ & $4.3^{\mathrm{b}}$ & $11.8^{\mathrm{ab}}$ \\
\hline $\mathrm{NaCl}$ & 0.1 & $7.3^{\mathrm{ab}}$ & $7.3^{\mathrm{ab}}$ & $6.3^{\mathrm{bc}}$ & $0.3^{\mathrm{a}}$ & $3.8^{\mathrm{b}}$ & $0.1^{\mathrm{a}}$ & $0.3^{\mathrm{a}}$ & $5.6^{\mathrm{bc}}$ & $5.7^{\mathrm{bcd}}$ & $9.9^{\mathrm{abc}}$ \\
\hline $\mathrm{CaCl}_{2}$ & 0.05 & $9.1^{\mathrm{c}}$ & $9.1^{\mathrm{c}}$ & $7.0^{\mathrm{c}}$ & $0.0^{\mathrm{a}}$ & $0.6^{\mathrm{a}}$ & $0.5^{\mathrm{a}}$ & $0.1^{\mathrm{a}}$ & $7.3^{\mathrm{c}}$ & $7.5^{\mathrm{d}}$ & $8.3^{\mathrm{bc}}$ \\
\hline $\mathrm{Ca} 100$ & 0.04 & $9.1^{\mathrm{c}}$ & $8.9^{\mathrm{bc}}$ & $7.3^{\mathrm{c}}$ & $0.2^{\mathrm{a}}$ & $0.6^{\mathrm{a}}$ & $0.2^{\mathrm{a}}$ & $0.0^{\mathrm{a}}$ & $7.0^{\mathrm{c}}$ & $7.0^{\mathrm{cd}}$ & $9.8^{\mathrm{abc}}$ \\
\hline $\mathrm{Ca} 200$ & 0.03 & $8.7^{\mathrm{bc}}$ & $9.0^{\mathrm{bc}}$ & $6.5^{\mathrm{bc}}$ & $0.0^{\mathrm{a}}$ & $0.7^{\mathrm{a}}$ & $0.0^{\mathrm{a}}$ & $0.1^{\mathrm{a}}$ & $7.1^{\mathrm{c}}$ & $7.2^{\mathrm{cd}}$ & $8.0^{\mathrm{bc}}$ \\
\hline
\end{tabular}

Different letters in the same column indicate significant difference $(P<0.05)$ by Tukey test. 
Table 3

Correlation coefficients between potato crisp descriptors and appraisal scores

\begin{tabular}{|c|c|c|c|c|c|c|c|c|}
\hline & Snap & Crispness & Potato & Sour & Salty & Bitter & Popcorn & Taste appraisal \\
\hline Crispness & $0.82^{* *}$ & 1 & & & & & & \\
\hline Potato & 0.11 & 0.12 & 1 & & & & & \\
\hline Sour & -0.08 & -0.11 & $-0.45^{* *}$ & 1 & & & & \\
\hline Salty & -0.02 & -0.04 & 0.02 & -0.10 & 1 & & & \\
\hline Bitter & 0.06 & -0.03 & -0.05 & -0.05 & -0.12 & 1 & & \\
\hline Popcorn & 0.07 & -0.07 & $-0.27^{* *}$ & -0.03 & -0.05 & -0.06 & 1 & \\
\hline Taste appraisal & $0.16^{*}$ & $0.19^{*}$ & $0.56^{* *}$ & $-0.58^{* *}$ & 0.09 & -0.03 & $-0.23^{* *}$ & 1 \\
\hline Overall appraisal & $0.26^{* *}$ & $0.27^{* *}$ & $0.59^{* *}$ & $-0.57^{* *}$ & 0.10 & -0.04 & $-0.20^{* *}$ & $0.92^{* *}$ \\
\hline
\end{tabular}

* Significant correlation at the 0.05 level.

** Significant correlation at the 0.01 level.

\subsection{Colour evaluation of potato crisps}

The sensory analyses were performed under IR-light, in order to exclude bias due to product colour. The surface colour was measured by means of a spectrophotometer. The results, also presented in Table 2, are expressed as the difference in colour compared to raw potato tissue $(\Delta E)$. Accordingly, a higher $\Delta E$ value corresponded to a darker and browner product.

The crisps, blanched in water containing citric or acetic acid appeared to be brighter compared to the control, although the difference was statistically not significant (Table 2). Interestingly however, crisps treated with L-lactic acid were significantly browner compared to the crisps treated with acetic or citric acid. Apparently, the L-lactic acid did not counteract but even promoted to some extent the browning. This seems unusual since the $\mathrm{pH}$ of the blanched potato slices was lowered to 4.8 by addition of L-lactic acid, as compared to the slices blanched in water (Table 1). Consequently, a reduced Maillard browning was expected. Yet, the difference in colour between the control crisps, blanched in water was not significant.

When free glycine or L-lysine were added to the blanching water, a darker coloured product was obtained upon frying, compared to the control (Table 2). This difference was mostly pronounced for L-lysine. This is not surprising since L-lysine is known as a very reactive amino acid in the Maillard reaction, due to the $\alpha$ - and $\varepsilon$-amino groups (Ajandouz \& Puigserver, 1999; Becalski, Lau, Lewis, \& Seaman, 2003). Also in combination with acetic acid, L-lysine appeared to induce more browning compared to glycine. Moreover, at the applied concentrations, both amino acids could counteract the inhibition of browning, caused by addition of acetic acid.

$\mathrm{NaCl}$ promoted to some extent the surface browning, although not significantly compared to the control (Table 2). Also the addition of $\mathrm{CaCl}_{2}$, eventually in combination with calcium-L-lactate, did not significantly change the surface colour, compared to the control. Previously, it was also shown that addition of $\mathrm{NaCl}$ and $\mathrm{CaCl}_{2}$ to potato strips did not change the surface colour upon subsequent frying (Bunger et al., 2003; Franke et al., 2005; Gökmen \& Senyuva, 2007), although other studies found a reduced browning upon addition of $\mathrm{NaCl}$ (Santis, Mendoza, Moyano, Pedreschi, \& Dejmek, 2007; Pedreschi et al., 2007; Pedreschi et al., 2007).

From the colour measurements, it could thus be concluded that the addition of citric and acetic acid produced brighter coloured crisps, in contrast to L-lactic acid. Addition of glycine or L-lysine gave rise to more browning upon frying. This could counteract the browning-inhibiting effect of acetic acid. $\mathrm{CaCl}_{2}$, calcium-L-lactate or $\mathrm{NaCl}$ did not significantly change product colour, compared to the control blanched in distilled water. However, it has to be mentioned that it is not always the goal to produce crisps with a darker colour. Therefore, the addition of free amino acids could be more useful in the production of French fries, where a too pale colour is generally not wanted.

Furthermore, no correlation was found between browning $(\Delta E)$ and the acrylamide content in potato crisps. The L-lysine or glycine treated crisps were quite dark coloured, but had a lower acrylamide contamination compared to e.g. crisps, blanched in $\mathrm{NaCl}$. This discrepancy was already discussed in previous studies upon applying several additives to fried potato products (Low et al., 2006).

\subsection{Concluding remarks and perspectives}

The challenge of this study was to find strategies to minimize acrylamide formation while maintaining the expected product quality for the consumer. The results revealed that both aspects are closely linked to each other. An integrated approach is thus required, which combines the knowledge how to reduce acrylamide with the corresponding product-specific quality aspects, such as colour, texture and taste. Several additives, such as organic acids, $\mathrm{NaCl}$ or $\mathrm{Ca}^{2+}$, not only reduced the final acrylamide content, but also lowered the absorption of oil upon frying. This perfectly fits within the ongoing consumer trend to move towards healthier and low-fat products in order to counteract obesity and coronary heart diseases.

Yet, the use of these additives might also stimulate other reactions upon frying, which may negatively influence product safety. The addition of salts such as $\mathrm{NaCl}$ and $\mathrm{CaCl}_{2}$ prior to the frying step might increase the rate of oil degradation upon subsequent frying (Mehta \& Swin- 
burn, 2001; Padilla, 2005). This would lead to a more rapid oil turnover rate in the industrial frying installation, causing extra production costs, and needs to be further investigated.

Above-mentioned results show that the applied components and concentration levels should be well chosen in order not to generate product-foreign flavours or undesired product colour. Possible sensory defects occurring as a result of acrylamide-lowering additives such as citric acid, could in some cases be covered up using flavourings, such as sodium salt, paprika or onion (Mottur, 1989; Reyes \& Barringer, 2005). Additional product optimization techniques are thus available in order to (further) improve sensorial product quality.

\section{Acknowledgements}

This research was financially supported by the BOF of Ghent University and by the Belgian Federal Service of Public Health, Safety of the Food Chain and the Environment. The cooperation of Purac Biochem (The Netherlands) and Brenntag (Belgium) was greatly appreciated.

\section{References}

Aguilar, C. N., AnzalduaMorales, A., Talamas, R., \& Gastelum, G. (1997). Low-temperature blanch improves textural quality of French fries. Journal of Food Science, 62, 568-571.

Ajandouz, E. H., \& Puigserver, A. (1999). Nonenzymatic browning reaction of essential amino acids: Effect of $\mathrm{pH}$ on caramelization and Maillard reaction kinetics. Journal of Agricultural and Food Chemistry, 47, 1786-1793.

Becalski, A., Lau, B. P. Y., Lewis, D., \& Seaman, S. W. (2003). Acrylamide in foods: Occurrence, sources, and modeling. Journal of Agricultural and Food Chemistry, 51, 802-808.

Bunger, A., Moyano, P., \& Rioseco, V. (2003). NaCl soaking treatment for improving the quality of french-fried potatoes. Food Research International, 36, 161-166.

Carpenter, R. P., Lyon, D. H., \& Hasdell, T. A. (2000). Guidelines for sensory analysis in food products. Development and quality control. Gaithersburg, MD: Aspen Publishers Inc.

Claeys, W. L., De Vleeschouwer, K., \& Hendrickx, M. E. (2005). Effect of amino acids on acrylamide formation and elimination kinetics. Biotechnology Progress, 21, 1525-1530.

Egan, H., Kirk, R., \& Sawyer, R. (1981). Pearson's chemical analysis of foods. Edinburgh: Churchill Livingstone.

Franke, K., Sell, M., \& Reimerdes, E. H. (2005). Quality related minimization of acrylamide formation - An integrated approach. In M. Friedman \& D. Mottram (Eds.), Chemistry and safety of acrylamide in food (pp. 357-369). New York: Springer.

Gökmen, V., \& Senyuva, H. Z. (2007). Acrylamide formation is prevented by divalent cations during the Maillard reaction. Food Chemistry, 103, 196-203.

Grob, K., Biedermann, M., Biedermann-Brem, S., Noti, A., Imhof, D., Amrein, T., et al. (2003). French fries with less than $100 \mu \mathrm{g} / \mathrm{kg}$ acrylamide. A collaboration between cooks and analysts. European Food Research and Technology, 217, 185-194.

ISO 6658 (2005). International Standard: Sensory analysis - methodology - general guidance.

Jackson, L. S., \& Al-Taher, F. (2005). Effects of consumer food preparation on acrylamide formation. In M. Friedman \& D. Mottram (Eds.), Chemistry and safety of acrylamide in food (pp. 447-465). New York: Springer.
Khalil, A. H. (1999). Quality of french fried potatoes as influenced by coating with hydrocolloids. Food Chemistry, 66, 201-208.

Kim, C. T., Hwang, E. S., \& Lee, H. J. (2005). Reducing acrylamide in fried snack products by adding amino acids. Journal of Food Science, 70, C354-C358.

Kita, A., Bråthen, E., Knutsen, S. H., \& Wicklund, T. (2004). Effective ways of decreasing acrylamide content in potato crisps during processing. Journal of Agricultural and Food Chemistry, 52, 70117016.

Lindsay, R. C., \& Jang, S. J. (2005). Chemical intervention strategies for substantial suppression of acrylamide formation in fried potato products. In M. Friedman \& D. Mottram (Eds.), Chemistry and Safety of Acrylamide in Food (pp. 393-404). New York: Springer.

Low, M. Y., Koutsidis, G., Parker, J. K., Elmore, J. S., Dodson, A. T., \& Mottram, D. S. (2006). Effect of citric acid and glycine addition on acrylamide and flavor in a potato model system. Journal of Agricultural and Food Chemistry, 54, 5976-5983.

Mehta, U., \& Swinburn, B. (2001). A review of factors affecting fat absorption in hot chips. Critical Reviews in Food Science and Nutrition, 41, 133-154.

Mestdagh, F., Maertens, J., Cucu, T., Delporte, K., Van Peteghem, C. \& De Meulenaer, B. (2007). Impact of additives to lower the formation of acrylamide in a potato model system through $\mathrm{pH}$ reduction and other mechanisms. Food Chemistry, in press, doi:10.1016/j.foodchem.2007. 07.013 .

Mestdagh, F. J., De Meulenaer, B., Van Poucke, C., Detavernier, C., Cromphout, C., \& Van Peteghem, C. (2005). Influence of oil type on the amounts of acrylamide generated in a model system and in French fries. Journal of Agricultural and Food Chemistry, 53, 6170-6174.

Miranda, M. L., \& Aguilera, J. M. (2006). Structure and texture properties of fried potato products. Food Reviews International, 22, 173-201.

Mottur, G. P. (1989). A scientific look at potato chips - The original savory snack. Cereal Foods World, 34, 620-626.

O'Mahony, M. (1986). Sensory evaluation of food: statistical methods and procedures. New York: Marcel Dekker Inc.

Padilla, J. (2005). In Industrial frying systems. Fifth international symposium on deep-fat frying. Healthier and safer fried foods in a changing marketplace, San Francisco, CA, 20-22 February 2005.

Park, Y. W., Yang, H. W., Storkson, J. M., Albright, K. J., Liu, W., Lindsay, R. C., et al. (2005). Controlling acrylamide in french fry and potato chip models and a mathematical model of acrylamide formation - Acrylamide: Acidulants, phytate and calcium. In M. Friedman \& D. Mottram (Eds.), Chemistry and safety of acrylamide in food (pp. 343-356). New York: Springer.

Paul, A. A., \& Southgate, D. A. T. (1978). The composition of foods (4th ed.). London: HMSO.

Pedreschi, F., Bustos, O., Mery, D., Moyano, P., Kaack, K., \& Granby, K. (2007). Color kinetics and acrylamide formation in $\mathrm{NaCl}$ soaked potato chips. Journal of Food Engineering, 79, 989-997.

Pedreschi, F., Kaack, K., \& Granby, K. (2004). Reduction of acrylamide formation in potato slices during frying. $L W T$ - Food Science and Technology, 37, 679-685.

Pedreschi, F., Kaack, K., Granby, K., \& Troncoso, E. (2007). Acrylamide reduction under different pre-treatments in French fries. Journal of a Food Engineering, 79, 1287-1294.

Pedreschi, F., Moyano, P., Santis, N., \& Pedreschi, R. (2007). Physical properties of pre-treated potato chips. Journal of Food Engineering, 79, 1474-1482.

Reyes, C., \& Barringer, S. A. (2005). Evenness of seasoning measured by image analysis, colorimetry and sensory evaluation. Journal of Food Processing and Preservation, 29, 369-377.

Rimac-Brncic, S., Lelas, V., Rade, D., \& Simundic, B. (2004). Decreasing of oil absorption in potato strips during deep fat frying. Journal of Food Engineering, 64, 237-241. 
Santis, N., Mendoza, F., Moyano, P., Pedreschi, F., \& Dejmek, P. (2007). Soaking in a $\mathrm{NaCl}$ solution produce paler potato chips. $L W T-$ Food Science and Technology, 40, 307-312.

Stadler, R. H., Robert, F., Riediker, S., Varga, N., Davidek, T., Devaud, S., et al. (2004). In-depth mechanistic study on the formation of acrylamide and other vinylogous compounds by the Maillard reaction. Journal of Agricultural and Food Chemistry, 52, 5550-5558.

Varela, P., Salvador, A., \& Fiszman, S. M. (2007). The use of calcium chloride in minimally processed apples: A sensory approach. European Food Research and Technology, 224, 461-467. 